\title{
A RELAÇÃO TRABALHISTA DE COOPEATIVAS DE ECONOMIA SOLIDÁRIA E A FORMAÇÃO DE LEDERANÇAS DENTRO DOS GRUPOS
}

\author{
Maria Luiza Souza Mendes de Araújo'; ${ }^{1}$ Iracema Raimunda Brito Neves Aragão²
}

1. Bolsista PIBIC/CNPq, Graduando Direito, Universidade Estadual de Feira de Santana, e-mail: marialuizasma@gmail.com

2. Orientador, DCIS, Universidade Estadual de Feira de Santana, e-mail: irbn31@ yahoo.com.br

PALAVRAS-CHAVE: Economia Solidária. Relação de trabalho. Liderança.

\section{INTRODUÇÃO}

Diante da conjuntura econômica e social brasileira, a economia popular e solidária pode ser tratada como uma saída plausível para as pessoas que acabam sofrendo os efeitos com a crise no modo de produção capitalista, principalmente com o quadro de demissão que assolam diversas empresas. Por isso, busca-se estudar as relações de trabalho que se constrói dentro desta nova forma de se organizar, para se perceber qual a dificuldade trazida pelos grupos diante das outras experiências que dificultam ou facilitam a adaptação deles a esta nova organização.

Acontece que a organização popular e solidária de um grupo trabalha a ideia de hierarquia que o sistema capitalista impõe como necessário para a concepção de qualquer estrutura de gestão, principalmente diante da formação de lideranças. Por isso, o artigo tem como tema a relação de trabalho construída em um grupo de economia popular e solidária no início do processo de incubação, e suas peculiaridades para não configurar uma forma de burlar as leis e garantias trabalhistas, principalmente quando há um líder conduzindo o dia-adia do grupo.

O objetivo deste trabalho é observar as relações de trabalho que se formam dentro do grupo e como conciliar a consolidação da autogestão com a presença de um líder, sem criação de laços de subordinação que descaracterizam a solidariedade de uma organização.

Acrescenta-se ainda os ideais da economia solidária, com isso, os conceitos do grupo são compatíveis com o que é pensado sobre esse modo de produção por Paul Singer ${ }^{1}$ :

"A economia solidária é outro modo de produção, cujos princípios básicos são a propriedade coletiva ou associação do capital e o direito à liberdade individual. A aplicação desses princípios une todos os que produzem numa única classe de trabalhadores que são possuidores de capital por igual em cada cooperativa ou sociedade econômica. [...] (SINGER, Paul, 2002, pg.10)".

No que concerne às relações de trabalho, a construção deve ser sempre de igualdade dentro do grupo, independente da presença do líder. Mesmo a liderança, em diversos casos é extremamente necessária para a gestão e condução das atividades do dia-a-dia do grupo. Acontece que, mesmo com o líder, não se admite a formação de hierarquias, por isso a importância de se construir lideranças solidárias, as quais devem ser porta-voz da vontade da maioria dos membros do grupo, com ações formalizadas e decididas pelos membros como um todo desta coletividade, é o que SINGER, (2002) explica como decisões de baixo para cima.

A luz desses fatores observa-se o Grupo Formiga tentando identificar os comportamentos e formas de gestão compatíveis ou não com esse modo de produção, sem deixar de considerar a figura bem delimitada de um líder, diante da experiência na atuação de fornecimento de alimentos para outro programa ligado a Prefeitura da Feira de Santana, bem

\footnotetext{
${ }^{1}$ SINGER, Paul. Introdução à economia solidária. São Paulo: Perseu Abramo, 2002.
} 
como diante da atuação dos membros do grupo dentro da associação de moradores em que se inserem.

\section{MATERIAL E MÉTODOS OU METODOLOGIA (ou equivalente)}

A metodologia utilizada foi um estudo doutrinário sobre o tema, pra esclarecer este modo de produção e como se dá a organização das relações de trabalho, bem como sobre a formação de lideranças e perfis solidários para esta função. Utilizou-se de uma análise da lei de cooperativas, bem como de outras leis que tratem do tema, para que se possa entender como o ordenamento jurídico brasileiro trata dos direitos trabalhistas daqueles que se inserem neste modo de produção diferenciado, bem como os critérios que um grupo deste tipo deve seguir para gozar dos benefícios de uma cooperativa e não configurar apenas uma forma de driblar as leis trabalhistas.

Por fim, vários foram os momentos de observação do grupo, seja no processo de seleção, seja em oficinas de formação do grupo, ou demais encontros, bem como das observações de necessidade do dia-a-dia na cantina ou por outros meios de comuniação.

\section{RESULTADOS E/OU DISCUSSÃO (ou Análise e discussão dos resultados)}

É importante discutir que a autogestão além de ser de extrema importância para a identificação de um grupo de economia solidária, ao mesmo tempo é o requisito mais complicado de se construir e adaptar os membros do grupo a este tipo de organização, isso porque, normalmente, o perfil de pessoas participantes de em empreendimento solidário são aqueles que na sua vida só se colocaram em experiências de subordinação, comumente como subordinados em suas experiências anteriores de trabalho.

Considerar uma liderança legítima dentro desses grupos não se limita na questão de ser uma pessoa escolhida pelos colegas. Além disso, é preciso manter a estrutura na tomada de decisões, mantendo o sentido das ordens de baixo para cima, ou seja, conforme pensamento de SINGER (2006), mesmo com a formação de lideranças e até mesmo órgãos de diretoria, as decisões devem ser tomadas por todos os membros e executadas com atos de gestão pelos líderes ou diretos, mantendo-se assim o perfil autogestionário do grupo.

Quanto a liderança e a ocorrência de subordinação ou quebra da autogestão dentro de um grupo, a visão não pode ser tão limitada. O que se defende é que as lideranças de mostram muito importantes para o desenvolvimento do grupo. Acontece que os elementos da liderança convencional, como confiança, união, comunicação, estratégias de condução de ações e tomadas de decisões podem apresentar características diferentes para se adaptarem ao perfil solidário necessário para estes empreendimentos.

É importante compreender que a liderança não é considerada apenas um atributo individual, mas sim coletivo também. Uma liderança também pode produzir e fortalecer um espírito de coletividade, de solidariedade, agregando valor no memento das tomadas de decisão e busca da melhor direção do grupo para aquele momento. O que se entende é que um líder que demonstre zelar pelos princípios da economia solidária, principalmente no que diz respeito à democracia e autogestão, tendem a conduzir os demais membros do grupo a agirem daquela forma, afastando o risco da submissão. O poder de construir a identidade de um grupo através da identidade de um líder, no entanto, é uma via de mão dupla. Se pautada nos princípios corretos, é grande facilitador de estruturação ideológica dentro de um empreendimento, no entanto, a mínima característica antidemocrática também tem o poder de reproduzir a estrutura dos meios de produção convencionalmente capitalistas.

No estudo das lideranças, é de extrema importância analisar a história de vida e experiências de cada pessoa do grupo. A depender da formação de cada um, a tendência à liderança se mostra mais latente ou não. Normalmente, dentro desses grupos populares, aqueles que já demonstram participação e interesse em movimentos sociais, por exemplo, 
demonstram uma tendência a influenciar outras pessoas sobre suas ideologias na formação de um perfil grupal de extrema relevância na construção da identidade da equipe.

Nota-se que a atuação dentro das questões da comunidade muitas vezes se mistura com as questões organizacionais dentro da atuação nas cantinas, mas isso não se mostra, em regra, um ponto negativo. As experiências de divisão de tarefas e tomada de decisões democráticas fortalecem a atuação dentro dos preceitos da economia popular e solidária, mesmo que em alguns momentos perceba-se que há a demarcação exacerbada de líderes, até por meio de uma centralização de funções e decisões cotidianas, percebe-se que o tempo de existência e atuação em outros espaços do grupo demonstram que cada um tem consciência do seu papel dentro do grupo, do valor de sua atuação e da importância de exigir, participar e limitar em certos pontos a atuação da pessoa que fora colocada no papel de líder.

No entanto, além de identificar o perfil de liderança, o trabalho preocupa-se em discutir se este "poder" é utilizado para subordinar os demais membros do grupo ou não. É de extrema importância que os líderes em empreendimentos solidários busquem valorizar o posicionamento de cada indivíduo, bem como a sua mão de obra. A não hierarquização do grupo, mesmo diante de polos de condução, é o ponto crucial para o não desvirtuamento do trabalho cooperado/associado em relação a forma capitalista comum de organizar o trabalho.

\section{CONSIDERAÇÕES FINAIS (ou Conclusão)}

Apesar do entendimento de VERONESE e SCHOLZ (2013), da questão cíclica da percepção do grupo sobre liderança e organização do trabalho, na observação, mesmo recente do último grupo que fora selecionado para a cantina (Formiga), percebe-se que eles têm uma visão abrangente em relação às permutas de funções, e da importância de todos saberem desenvolver todas as atividades a serem executadas até para a valorização da mão-de-obra de cada membro e para a manutenção do bom funcionamento da cantina em situações de emergência. No entanto, percebe-se ao mesmo tempo, uma liderança muito centralizada, talvez até incompatível com a visão geral do grupo sobre a permuta de funções. Até o momento, acredita-se que, mesmo diante desta característica, não é possível afirmar que a liderança tem prejudicado ou comprometido à democracia por completo na tomada de decisões dentro do grupo, no entanto, identifica-se a necessidade de ações da incubadora a fim de incentivar a democratização e coletivização da liderança também.

Acerca desta situação, acredita-se que esta estrutura organizacional seja consequência da atuação nos termos da associação relativa a comunidade e ao trabalho que desenvolvem dentro de outros programas de desenvolvimento, além da característica pessoal daquele que vai tomando este papel.

Diante das observações, é possível notar que o grupo Formiga, por já está associado há anos para o trabalho no ramo de fornecimento de alimentos em outros programas da prefeitura, além de outras questões dentro da comunidade, a liderança ainda não demonstra ser totalmente solidária, principalmente diante da centralização de muitas funções e execuções de atos de gestão em uma pessoa.

Apresar da experiência do grupo, o novo cenário de trabalho afeta bastante a atuação e a auto-afirmação de cada membro do coletivo. Acontece que a própria liderança, diante de novas situações de trabalho, que talvez estejam cobrando uma convivência e uma organização mais acentuada, em alguns momentos, não consiga lidar corretamente com algumas situações. $\mathrm{O}$ que se quer dizer é que, nesta situação inicial do grupo, principalmente por já ter uma figura enquanto líder, a pessoa desta função, acaba por perder algumas 
características solidárias que não estejam bem consolidadas. Por isso, observou-se como característica positiva deste grupo a consciência do papel e do poder que cada membro possui, de forma que este comportamento se mostra muito relevante para ações destinadas ao empoderamento do grupo como um todo afora a figura do líder.

Em muitos casos pensamos que o perfil do líder que deve ser trabalhado para que o grupo cresça em sua autogestão, no entanto, o empoderamento do grupo como um todo deve ser alvo de ações para que eles mesmo consigam limitar o poder e controlar a legitimidade das decisões deste líder para que ele mantenha seu perfil solidário, sem influenciar individualmente nas questões que lidam principalmente com a entrada e saída, funções e postos de trabalho de cada membro.

Quanto à mudança de perfil do líder do grupo, acredita-se que isso será possível com a atuação da Incubadora na conscientização e estímulo a formação de lideranças coletivas, principalmente depois de todos os membros experimentarem todas as funções do grupo. $\mathrm{O}$ objetivo é tentar descentralizar a liderança e garantir que mais pessoas se sintam à vontade para expor seu posicionamento em qualquer ocasião, além de tentar fazer com que todos do grupo se sintam preparados e capazes de desempenhar funções de gestão, bem como resolver problemas imediatos sem depender da atuação de um líder centralizado.

No entanto, de uma forma geral, até o momento, a formação de liderança nesse grupo não se mostrou uma forma de subordinar a mão de obra dos demais membros do grupo, muito por conta da autoafirmação dos demais membros. A atuação e comunicação entre grupo e incubadora das situações urgentes parecem ser mais eficientes diante da presença deste líder, bem como, a sua presença força a consolidação de um perfil ideológico voltado para os princípios da economia popular e solidária. Acredita-se que uma semente está sendo plantada e com a atuação da incubadora ela pode desenvolver uma nova visão de liderança mais democrática para com o grupo, bem como melhorar o empoderamento dos membros que estão fora da liderança para que eles consigam limitar a atuação do líder apenas àquilo que é legitimado a fazer.

\section{REFERÊNCIAS}

SINGER, Paul. Introdução à economia solidária. São Paulo: Perseu Abramo, 2002.

NELSON, Rocco Antonio Rangel Rosso. Das cooperativas de trabalho: instrumento usado na dissimulação da relação de emprego e consequente alijamento dos direitos sociais. Revista de Direito do Trabalho, São Paulo, v. 39, n. 153, p. 73-90, set./out. 2013.

VERONESE, Marília Veríssimo. A Economia Solidária e a Formação de Lideranças Democráticas. Revista Diálogo. No 18. 29/09/2011.

VERONESE, Marília Veríssimo. SCHOLZ, Robinson. A difícil construção da liderança solidária compartilhada. Século XXI, Revista de Ciências Sociais, v.3, nº 2, p.41-64, jul/dez.2013.

SCHOLZ, Robinson Henrique. VERONESE, Marília Veríssimo. Liderança na Economia Solidária: O caso da Cooperativa Metalúrgica Cooperei. ESAC - Economia Solidária e Ação Cooperativa. Julho/Dezembro de 2007.

PAULI, J. BENDER, N. ZANELLA, W. Perfil de Liderança Solidária em Empreendimentos de Economia Solidária. PERSPECTIVA, Erechim. v.37, n.138, p.93-104, junho/2013. 